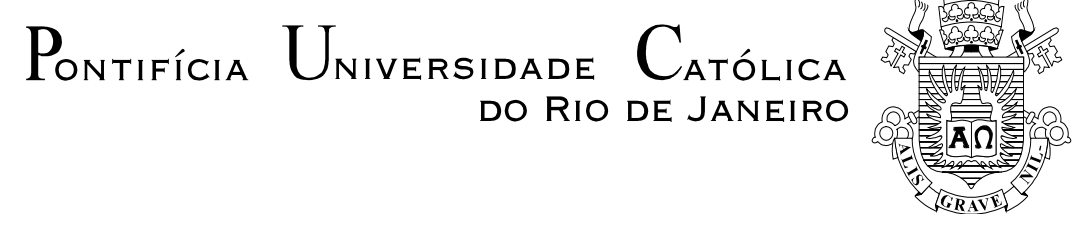

Esley Rodrigues de Jesus

Swap de preços de liquidação da diferença:

o caso de parques eólicos

Dissertação de Mestrado

Dissertação apresentada ao Programa de Pós-Graduação em Administração de Empresas da PUC-Rio como requisito parcial para obtenção do título de Mestre em Administração de Empresas.

Orientador: Prof. Leonardo Lima Gomes

Rio de Janeiro

Abril de 2015 


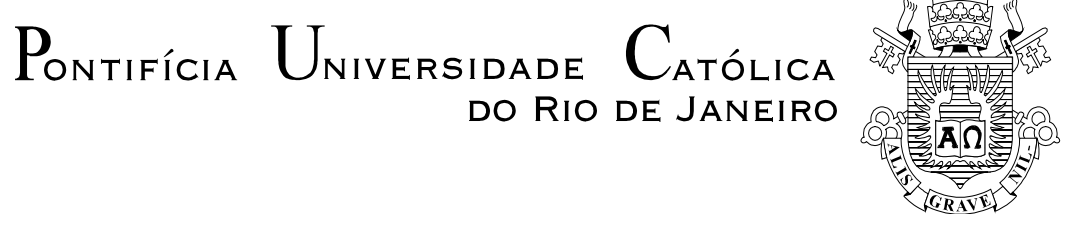

Esley Rodrigues de Jesus

\section{Swap de preços de liquidação da diferença: o caso de parques eólicos}

Dissertação apresentada como requisito parcial para obtenção do grau de Mestre pelo Programa de PósGraduação em Administração de Empresas da PUC-Rio. Aprovada pela Comissão Examinadora abaixo assinada.

Prof. Leonardo Lima Gomes

Orientador

Departamento de Administração - PUC-Rio

Prof. Marcelo Cabus Klotzle Departamento de Administração - PUC-Rio

Prof ${ }^{a}$. Marta Corrêa Dalbem

Universidade do Grande Rio

Profa. Mônica Herz Vice-Decana de Pós-Graduação do CCS - PUC-Rio

Rio de Janeiro, 09 de abril de 2015 
Todos os direitos reservados. É proibida a reprodução total ou parcial do trabalho sem autorização da universidade, do autor e do orientador.

\section{Esley Rodrigues de Jesus}

Graduou-se em Ciências Navais com habilitação em Mecânica pela Escola Naval em 2010. Serve há cinco anos no Batalhão Logístico de Fuzileiros Navais, tendo exercido diversas funções, das quais destacam-se gerente de transportes e agente financeiro. Realizou curso de analista em logística e cadeia de suprimentos pelo ILOS em 2012 e MBA em Finanças Corporativas na FGV em 2014. Atualmente cursa mestrado em Administração de Empresas com ênfase em finanças no IAG, Pontifícia Universidade Católica do Rio de Janeiro.

Ficha Catalográfica

de Jesus, Esley Rodrigues

Swap de preços de liquidação da diferença: o caso de parques eólicos / Esley Rodrigues de Jesus; orientador: Leonardo Lima Gomes. - 2015.

37 f.; $30 \mathrm{~cm}$

Dissertação (mestrado) - Pontifícia Universidade Católica do Rio de Janeiro, Departamento de Administração, 2015.

Inclui bibliografia

1. Administração - Teses. 2. Energia elétrica. 3. PLD. 4. Sustentabilidade. 5. Hedge. 6. Swap. I. Gomes, Leonardo Lima. II. Pontifícia Universidade Católica do Rio de Janeiro. Departamento de Administração. III. Título.

CDD: 658 


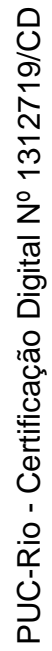

Para (e em memória de) meu pai Elides pelo exemplo de vida. 


\section{Agradecimentos}

A Deus, acima de todas as coisas, e a Jesus Cristo, seu único filho, autor e consumador de minha fé.

Aos meus amigos Vinícius Guerra, Sérgio, Robson, Roberto, Marcelo, Júnior Rodrigues, Diego e Vinícius Lopes, cujos laços ora forjados certamente permanecerão pelos anos vindouros.

Aos meus avós, Lielza e José Reis, pela força e determinação que me serviram de exemplo.

À minha mãe, Sra. Sueli, pela ajuda e compreensão nos momentos difíceis.

À minha esposa, Sra. Débora, pelo carinho, amor e paciência. 


\section{Resumo}

de Jesus, Esley Rodrigues; Gomes, Leonardo Lima (Orientador). Swap de preços de liquidação da diferença: o caso de parques eólicos. Rio de Janeiro, 2015. 37p. Dissertação de Mestrado - Departamento de Administração, Pontifícia Universidade Católica do Rio de Janeiro.

O atual panorama do mercado energético no Brasil permite aos produtores de energia realizar operações de swap de preços, o que diminui os riscos intrínsecos da operação, além de garantir, ocasionalmente, melhores lucros. Devido à diferenças existentes entre as demandas dos diversos submercados de energia, podese arbitrar os preços, de modo a minimizar as perdas. Tendo por objetivo encontrar melhores formas de realizar este swap e utilizando-se de duas mil séries dos preços projetados de liquidação das diferenças (PLD), dos anos de 2016, 2017 e 2018, analisou-se a magnitude dos riscos considerando-se o hedge especificamente para parques eólicos no nordeste com venda no sudeste. Os resultados encontrados indicam que apesar da magnitude do risco ser grande, os swaps de energia são bastante eficazes em sua mitigação.

\section{Palavras-chave}

Energia Elétrica; PLD; Sustentabilidade; Hedge; Swap. 


\section{Abstract}

de Jesus, Esley Rodrigues; Gomes, Leonardo Lima (Advisor). Settlement price of differences swap: the case of wind-parks. Rio de Janeiro, 2015. 37p. MSc Dissertation - Departamento de Administração, Pontifícia Universidade Católica do Rio de Janeiro.

The panorama of the energy market in Brazil allows energy producers to make swap operations with prices, decreasing the intrinsic risks of operation, besides ensuring, occasionally, better profits. Due to the difference between the demands of the various energy submarkets, they may arbitrage the prices to minimize their losses. With the objective to find better ways to make this swap, and working on two thousand series of the settlement price of differences, from the years of 2016, 2017 and 2018, it was possible to analyze the magnitude of the risks, considering the hedge. Despite the results, the Brazilian energy infrastructure is highly dependent on rainfall patterns, showing clear weakness in drought periods. A higher investment in the sustainable energy sector, is necessary in order to ensure a more continuous supply, taking into account the experience of other countries.

\section{Keywords}

Electric energy; settlement price of differences; sustainability; hedge; swap 


\section{Sumário}

1. INTRODUÇÃO

1.1. Contextualização 11

1.2. Objetivo e Questão de Pesquisa 12

1.3. Relevância do Trabalho 12

1.4. Organização da Dissertação 13

2. SETOR ELÉTRICO BRASILEIRO E REFERECIAL TEÓRICO 14

2.1. Legislação pertinente ao funcionamento do Setor Elétrico Brasileiro (SEB) 14

2.2. Principais Instituições do SEB: ONS, Aneel e CCEE 16

2.3. Previsão e Simulação de Preços 19

2.4. Referencial Teórico Pertinente 20

3. ENERGIA EÓLICA NO BRASIL E SUA COMERCIALAZAÇÃO 23

3.1. Um Breve Histórico Mundial 23

3.2. O Potencial de Crescimento da Energia Eólica no Brasil 24

3.3. A Evolução Regulatória e Comercial no Brasil 25

3.4. Modelo Atual de Comercialização de Energia 26

3.5. Contratação de Energia no ACR: Leilões de Energia 27

3.6. Contratação no ACL e a Diferença de PLDs Entre Submercados 28

4. RESULTADOS E ANÁLISE 29

5. CONCLUSÕES E SUGESTÕES PARA TRABALHOS FUTUROS 34

REFERÊNCIAS BIBLIOGRÁFICAS 36 


\section{Lista de figuras}

Figura 1: Evolução da Capacidade Instalada de Geração Eólica no Mundo. 23

Figura 2: Atlas Eólico Brasileiro. $\quad 24$

Figura 3: Comparativo gráfico entre os PLDs Médios SE x NE (2015). 29

Figura 4: Distribuição de frequências da média das diferenças dos PLD. 30

Figura 5: Produção de energia de usina eólica. 31

Figura 6: Valores Mensais em Risco. 32

Figura 7: Simulação - swap 12 MWmed. 33 


\section{Lista de tabelas}

Tabela 1: Principais características dos ambientes de contratação. 15

Tabela 2: PLD médio esperado de 2015. 


\section{Introdução}

\section{1}

\section{Contextualização}

Ao final de 2009, a capacidade instalada em plantas de geração eólica atingia a marca mundial de 158,5 GW (GWEC, 2010) no mundo. O crescimento era e continua exponencial. Cerca de 50\% das plantas eólicas em operação no final do ano de 2009 encontravam-se na Europa, sobretudo na Alemanha e na Espanha. Na América Latina, com pouco mais de 1,2 GW de capacidade instalada ao final de 2009, o Brasil era o destaque regional. Até 2009, portanto, já era observada uma tendência de crescimento exponencial da energia eólica no mundo, e no Brasil não foi diferente.

O Brasil é uma potência energética, e a energia eólica se insere nesse contexto. Somente o potencial do Nordeste (75 GW) já é maior que todo o consumo atual de energia no País (em torno de 65 GW). Os sinais de investimentos no setor eólico podem ser observados através dos resultados dos leilões de energia 2009, 2010 e 2011, que contrataram mais de 5.700 MW dessa fonte e foram implementados até 2014, levando a geração eólica de 1.093 MW (ANEEL, 2011) instalados em março de 2011 para 7.200 MW em 2014, um incremento de 85\% em pouco mais de 3 anos.

Em relação aos arranjos comerciais para empreendimentos de energia eólica no Brasil, a comercialização se dá em dois ambientes para celebração de contratos de compra e venda de energia: o Ambiente de Contratação Regulada (ACR), no qual participam Agentes de Geração e de Distribuição de energia; e o Ambiente de Contratação Livre (ACL), onde participam Agentes de Geração, Comercializadores, Importadores e Exportadores de energia e Consumidores Livres.

A comercialização de energia eólica para as distribuidoras só pode ser realizada através de leilões de energia. Por outro lado, os empreendedores podem também comercializar sua energia no ambiente livre, através dos contratos bilaterais, sendo este o foco desta dissertação. 
O mercado brasileiro de energia elétrica é dividido em quatro submercados interligados por longas linhas de transmissão, quais sejam: Norte, Nordeste, Sudeste/CO e Sul.

Um parque eólico pode contratar sua energia no ACL. Para fins de financiamento de longo prazo na estrutura de Project Finance é comum que esse contrato de venda seja de longo prazo, normalmente de 15 a 20 anos.

É corriqueiro também que o contrato seja celebrado no submercado sudeste onde há bem mais liquidez e uma demanda muito maior por energia. Dessa forma, como o parque eólico em geral se encontra no Nordeste (e esse é o caso abordado nessa dissertação), o investidor/empreendimento passa a correr um risco de submercado.

\section{2}

\section{Objetivo e Questão de Pesquisa}

Dado o contexto apresentado, o objetivo dessa dissertação é evidenciar o risco de submercado assumido por empreendimentos eólicos entre nordeste e sudeste com comercialização no ACL. O risco será mostrado por métricas como o Value at Risk a partir da simulação de preços spot para ambos os mercados.

Adicionalmente, deseja-se mostrar como o esse risco pode ser mitigado com instrumentos contratuais disponíveis no mercado, bem como qual é o nível de eficácia desses instrumentos.

Assim, pode-se condensar os objetivos propostos na seguinte questão de pesquisa: “Qual é a magnitude do risco de submercado enfrentado por empreendimentos eólicos que vendem energia no ACL no sudeste e qual é a eficácia de instrumentos de hedge disponíveis no mercado? ”

\section{3}

\section{Relevância do Trabalho}

A relevância do trabalho encontra-se em mostrar a eficácia dos instrumentos de proteção para o risco de submercado assumido por parques eólicos. Em sendo eficazes, esses instrumentos propiciam mais segurança para que se tenha mais investimentos em geração eólica com venda no sudeste. Investimentos esses impor- 
tantes por duas razões: primeiro por se tratar de investimentos em fontes renováveis de energia e segundo por propiciar mais energia de forma competitiva para a indústria, principal consumidor do ACL.

\section{4}

\section{Organização da Dissertação}

O trabalho está organizado da seguinte forma: após a introdução feita neste Capítulo, é realizada no Capítulo 2 uma descrição dos tópicos relevantes concernentes ao Setor Elétrico Brasileiro (SEB) bem como é apresentado o referencial teórico utilizado no trabalho. No Capítulo 3, faz-se a apresentação de como a energia eólica é regulamentada no Brasil e como em detalhes surge e se quantifica o risco de submercado. No Capítulo 4 são apresentados e discutidos os resultados e no Capítulo 5 são feitas as conclusões e sugestões para trabalhos futuros. 


\section{2 SETOR ELÉTRICO BRASILEIRO E REFERENCIAL TEÓRI- CO}

Neste capítulo será apresentado o referencial teórico utilizado na presente dissertação bem como a regulação base vigente do Setor Elétrico Brasileiro (SEB). Inicia-se pelos tópicos relevantes no que tange à regulação. Na próxima seção são abordadas as leis 10.847 e 10.848 que instituíram a divisão do mercado em dois ambientes, o livre e o regulado. Na seção seguinte, são descritas sucintamente as principais instituições do setor que serão citadas neste trabalho. Na seção 2.3 será apresentado como os preços são formados no mercado de curto prazo e simulados. Este tipo de simulação será realizada no exemplo numérico desenvolvido neste trabalho, cujos resultados são apresentados no capítulo 4. Adicionalmente, já são apresentadas algumas referências bibliográficas sobre o tema. Por fim, na seção 2.4, são citados os principais trabalhos e conceitos úteis à modelagem desenvolvida nesse trabalho.

\section{1}

\section{Legislação pertinente ao funcionamento do Setor Elétrico Brasileiro (SEB)}

A Lei 10.847, de 15 de março de 2004, foi responsável por criar a Empresa de Pesquisa de Energia (EPE), órgão diretamente ligado ao Ministério de Minas e Energia (MME), cuja principal missão é “prestar serviços na área de estudos e pesquisas destinadas a subsidiar o planejamento do setor energético, tais como energia elétrica, petróleo e gás natural e seus derivados, carvão mineral, fontes energéticas renováveis e eficiência energética, dentre outras.’’ Em outras palavras, a EPE é a grande responsável pelas diretrizes de longo prazo estipuladas pelo Executivo por meio do MME, que deve baseá-las de forma a garantir a melhor utilização do potencial energético brasileiro.

De mesma data, a Lei 10.848 dispõe as diretrizes sobre a comercialização de energia, estipulando a contratação regulada (realizada no Ambiente de Contratação Regulada - ACR, segmento em que são realizadas operações de compra e venda de energia através de licitações) ou livre (realizada no Ambiente de Contra- 
tação Livre - ACL, segmento que comercializa através de contratos bilaterais de forma livre) como forma de contratos entre os concessionários, permissionários e autorizados de serviços de instalações de energia elétrica, e entre estes e os consumidores. A Tabela 1 a seguir apresenta as principais características dos ambientes de contratação.

Tabela 1: Principais características dos ambientes de contratação.

\begin{tabular}{c|c}
\hline AMBIENTE DE & CARACTERÍSTICAS \\
CONTRATAÇão &
\end{tabular}

Energia deve ser proveniente de empreendimentos de geração existentes e novos empreendimentos de geração (que até a data de publicação do edital ainda não possuam concessão, permissão ou autorização ou que sejam parte de empreendimento existente que venha a ser objeto de ampliação). Nisto se enquadram energia importada ou gerada por meio de fontes alternativas.

A energia a ser contratada é definida pelo MME, subsidiado pela EPE, que além do montante de energia, também relaciona os empreendimentos elegíveis para o leilão, levando-se em conta a otimização técnico-econômica do parque hidrotérmico do SIN e de seu sistema de distribuição.

Regulado Os preços máximos de aquisição são definidos pelo MME nos leilões de energia proveniente de empreendimentos existentes.

Os Contratos de Comercialização de Energia Elétrica no Ambiente Regulado possui as modalidades de quantidade (o ponto de entrega será no centro de gravidade do submercado onde esteja localizado o empreendimento de geração e os custos decorrentes dos riscos hidrológicos são assumidos pelos agentes vendedores) ou de disponibilidade (risco hidrológico do comprador e possíveis exposições financeiras ao mercado de curto prazo legados ao vendedor) de energia elétrica

Contratação mediante operações de compra e venda de energia elétrica, envolvendo agentes concessionários, permissionários e autorizados de geração, comercializadores, importadores, exportadores de energia elétrica e consumidores livres, que devem também ser agentes da CCEE.

\begin{tabular}{l|l} 
Livre $\quad$ As relações comerciais são firmadas através de contratos bilaterais de com-
\end{tabular} pra e venda de energia elétrica, onde estão estabelecidos prazos e volumes. Os agente s vendedores poderão comercializar energia através de leilões promovidos pelos consumidores finais, oferta pública aditamento de contratos de fornecimento ou compra de energia. 
A Lei estipula que o Sistema Interligado Nacional (SNI) deve ser operado considerando-se a otimização dos recursos com vistas a alinhar a produção à demanda, a segurança operativa, restrições de transmissão, interligações nacionais e o custo do déficit de energia. Para tanto, segundo seu artigo $2^{\circ}$, determina que as licitações que regerão as contratações disporão sobre mecanismo que favoreçam a modicidade tarifaria, garantias e os limites de repasse dos custos da energia para o consumidor final.

O Decreto $\mathrm{n}^{\circ} 5.163$ de 30 de julho de 2004 regulamenta como devem ser realizadas a comercialização, o processo de concessões e de autorizações de energia elétrica, dando à ANEEL a responsabilidade pela expedição dos atos relativos à convenção, às regras e aos procedimentos de comercialização. Através deste decreto, conclui-se que o órgão responsável pela regulamentação dos contratos e licitações de energia é a ANEEL, mesmo quando realizados no ACL.

\section{2}

\section{Principais Instituições do SEB: ONS, Aneel e CCEE}

O ONS responde pela coordenação e controle das operações de todas as instalações produtoras e distribuidoras, relacionadas na geração e transmissão de energia elétrica no SIN, agindo em conjunto (regulado e fiscalizado) com a ANEEL. Como pessoa jurídica de direito privado, é constituído por diversos stakeholders do mercado energético, como empresas de transmissão, geração e distribuição, além de consumidores livres de grande porte, sendo capaz de estudar a demanda futura e planejar as necessidades de geração a fim de garantir uma melhor utilização do SIN em proveito do desenvolvimento econômico-social, de forma integrada, transparente, igualitária e neutra. Sua atuação sobre o SIN é baseado em dois fundamentos: Procedimentos de Rede (normas e requisitos técnicos que norteiam as responsabilidades do ONS e dos demais operadores para com o SIN) e as informações externas na operação do SIN (vindas basicamente do MME e da ANEEL). Neste contexto, o ONS fica com a tarefa de ampliação e reforço na rede básica, avaliação de curto prazo e futura das operações e integração de novas instalações ao SIN, dentre outras. Dentro destas atribuições, podemos concluir que a principal seria garantir ao sistema uma utilização dos recursos energéticos (em suma, o uso consciente e planejada dos recursos hídricos destinados à geração de 
energia) de modo a minimizar os custos totais de operação (nisto se incluindo geração, distribuição, transmissão e comercialização), de modo a garantir preços que possam ser interessantes ao bom desenvolvimento econômico do país.

O ONS é composto por 9 classes de membros associados e participantes, dente os quais vale ressaltar os agentes de geração, distribuição, transmissão, importadores, exportadores, MME, conselhos de consumidores. Esta estrutura de caráter privado possibilita maior independência quanto às suas resoluções e escolha de cadeiras importantes, como Presidente e Vice-Presidente, aprovar orçamento anual e contratação de auditores externos independentes.

Em conjunto com o Operador Nacional do Sistema, a Agência Nacional de Energia Elétrica funciona de forma a regular a produção, distribuição e comercialização de energia elétrica. Segundo a Lei $n^{0}$ 9.427/96 e o Decreto 2.335/97, a ANEEL também possui como tarefas fiscalizar as concessões (m qualquer esfera governamental) e estabelecer as tarifas de energia, também funcionando, por delegação de competência do governo federal, a outorga de concessões, permissões e autorizações para novos empreendimentos de energia elétrica e serviços de energia. A estrutura da ANEEL (Diretor-geral mais quatro diretores) são, após aprovados pelo Senado Federal, nomeados pelo Presidente da República para mandatos não coincidentes de quatro anos.

Por sua vez, a Câmara de Comercialização de Energia - CCEE foi criada pela Lei $\mathrm{n}^{0} 10.848 / 04$ e regulamentada pelo Decreto $\mathrm{n}^{0}$ 5.177/04 para viabilizar a comercialização de energia elétrica no Sistema Interligado Nacional - SIN, nos termos do artigo $4^{\circ}$ da referida lei.

A CCEE foi criada sob a forma de pessoa jurídica de direito privado, sem fins lucrativos, com autorização do Poder Concedente e fiscalização pela ANEEL.

Sendo constituída na forma de associação civil, a CCEE e integrada por titulares de concessão, permissão ou autorização, por outros agentes vinculados aos serviços e às instalações de energia elétrica, bem como pelos consumidores livres.

O Decreto $n^{\circ}$ 5.177/04 que regulamenta a Lei de criação da CCEE, hoje alterado pelo Decreto ${ }^{\circ} 6.353 / 08$, apresenta em seu artigo $2^{\circ}$ as principais atribuições da CCEE, a saber:

I - promover leilões de compra e venda de energia elétrica, desde que delegado pela ANEEL; 
II - manter o registro de todos os Contratos de Comercialização de Energia no Ambiente Regulado - CCEAR e os contratos resultantes dos leilões de ajuste, da aquisição de energia proveniente de geração distribuída e respectivas alterações;

III - manter o registro dos montantes de potência e energia objeto de contratos celebrados no Ambiente de Contratação Livre - ACL;

IV - promover a medição e o registro de dados relativos às operações de compra e venda e outros dados inerentes aos serviços de energia elétrica;

V - apurar o Preço de Liquidação de Diferenças - PLD do mercado de curto prazo por submercado;

VI - efetuar a contabilização dos montantes de energia elétrica comercializados e a liquidação financeira dos valores decorrentes das operações de compra e venda de energia elétrica realizadas no mercado de curto prazo;

VII - apurar o descumprimento de limites de contratação de energia elétrica e outras infrações e, quando for o caso, por delegação da ANEEL, nos termos da convenção de comercialização, aplicar as respectivas penalidades;

VIII - apurar os montantes e promover as ações necessárias para a realização do depósito, da custódia e da execução de garantias financeiras relativas às liquidações financeiras do mercado de curto prazo, nos termos da convenção de comercialização;

IX - efetuar a estruturação e a gestão do Contrato de Energia de Reserva, do Contrato de Uso da Energia de Reserva e da Conta de Energia de Reserva;

$\mathrm{X}$ - celebrar o Contrato de Energia de Reserva - CER e o Contrato de Uso de Energia de Reserva - CONUER.

O Estatuto Social da CCEE, bem como as suas alterações, é aprovado pela Assembléia Geral e homologado pela ANEEL.A estrutura e governança é formada pelos seguintes órgãos: Assembléia Geral, Conselho de Administração, Conselho Fiscal e Superintendência, cada qual com atribuições especificas estabelecidas na lei, decreto e no Estatuto Social. 


\section{3}

\section{Previsão e Simulação de Preços}

O preço de liquidação das diferenças - PLD é utilizado para liquidar a compra e a venda de energia no mercado de curto prazo. A formação do PLD se faz pela utilização dos dados considerados pelo Operador Nacional do Sistema (ONS) para a otimização da operação.

O Brasil adotou um formato de decisão de operação (geração de energia elétrica) centralizado realizado por modelos de otimização (um modelo de curto prazo acoplado a um de longo prazo, chamado Newave) cujo objetivo é minimizar o custo total de operação do sistema hidrotérmico ao longo de um horizonte de planejamento. Esses modelos utilizam o método de programação dinâmica dual estocástica (Pereira e Pinto, 1991).

A característica mais evidente de um sistema com geração hidroelétrica é poder utilizar a energia que está armazenada nos reservatórios para atender à demanda evitando, desta maneira, gastos de combustível com as unidades térmicas. Contudo, a disponibilidade de energia hidroelétrica está limitada pela capacidade de armazenamento nos reservatórios, o que impõe uma dependência entre a decisão operativa de hoje e os custos operativos no futuro, caracterizando um problema de otimização estocástica.

O problema de otimização pode ser resolvido por um algoritmo de programação linear. Além da decisão operativa ótima, o esquema de programação calcula os multiplicadores simplex, ou preços sombra, associados a cada restrição. Em particular, o PLD do sistema é o multiplicador simplex associado à restrição de atendimento à demanda, significando o custo de produção de $1 \mathrm{MWh}$ adicional no ponto ótimo de minimização de custos (em $\mathrm{R} \$ / M W h$ ).

A modelagem inclui a simulação de PLDs. Após a utilização de um modelo de otimização (Maceira et al, 1998) para calcular a política ótima de operação, são feitas simulações a fim de obter as séries de PLDs. A simulação pode ser feita através da geração de séries sintéticas utilizando um modelo Periódico Auto Regressivo - PAR(p) (Maceira e Bezerra, 1997). Cada série simulada de chuvas origina uma sequência mensal de PLDs. 
Nesta dissertação, foram simuladas 2000 séries de PLDs para o submercado sudeste e mais 2000 para o nordeste de forma concomitante. Foi utilizado o conjunto de dados de entrada do modelo Newave de agosto de 2014.

\section{4}

\section{Referencial Teórico Pertinente}

Apresenta-se a seguir um referencial teórico mais amplo que aborda questões ligadas às incertezas assumidas por investidores em projetos de fontes renováveis e mecanismos que vêm sendo utilizados para estimular investimentos em energia eólica dada a importância social destes. Na segunda parte do referencial, descrevem-se as principais citações acerca da definição e utilização do Value at Risk (VaR).

As energias renováveis são parte intrínseca do futuro, não somente pelos choques financeiros dos combustíveis e, consequentemente, do preço da energia, como também graças aos problemas ambientais que a humanidade enfrentaria.

Sendo assim, alguns métodos de avaliação de projetos de energia renovável englobam, também, os benefícios sociais e ambientais relativos à adoção de políticas menos nocivas ao meio ambiente. Menegaki (2007) discursa sobre quatro técnicas adotadas.

A energia eólica é uma das fontes renováveis e energia que vem crescendo mais rapidamente no mundo, além de ser considerada a melhor alternativa para a energia fóssil. Um dos grandes problemas em se garantir a perenidade da geração de energia e menores custos de manutenção está baseada na previsão dos ventos, que devem estar alinhados com a demanda do mercado alvo (nisto também entrando as perdas devido à distribuição da energia gerada), com a capacidade de geração instalada (custos com tecnologia e manutenção das turbinas, geradores e demais equipamentos do parque de geração) e com a oferta de geração e poder dos ventos (Jung e Brodwater, 2014).

Os projetos de energia, em geral, consideram como crucial o alinhamento entre a oferta e demanda de energia. Em mercados de preços a vista, o lucro do investidor fica bastante dependente deste alinhamento. Loisel et al. (2010) cita cinco principais tecnologias e técnicas que seriam capazes de mitigar a falta de previsão inerente às fontes renováveis de energia. 
Outra preocupação consiste na área a ser localizada as fazendas de vento (wind-farms), posto que existe certa crítica quanto à sua real utilidade por parte da sociedade em detrimento de outras fontes consideradas renováveis (como é o caso do brasil, a hidráulica). Algumas características, apontadas por Mirasgedis et al. (2014), são analisadas a fim de que haja uma avaliação do impacto visual causado pela instalação de usinas de energia eólica.

Na China, a questão da facilidade de crédito dado pelo governo, em conjunto com os benefícios financeiros oriundos dos créditos de carbono expandiram sobremaneira as áreas instaladas. Xu e Zhuan (2009) acreditam que, ao alcançar uma importância de 20\% na matriz energética de determinado país (WPP - Wind Power Penetration = capacidade de geração de energia eólica / pico de demanda), a energia eólica enfrentaria mais dificuldades econômicas que tecnológicas.

Como a área define a qualidade dos ventos, é bem plausível que ao se escolher o local da planta, também se esteja definindo (em parte) o futuro preço da energia a ser ali produzida. Além disso, determinados períodos apresentam ventos mais ou menos fortes, capazes de gerar mais ou menos energia. Isto está diretamente relacionado ao montante oferecido de energia e, mais uma vez, ao alinhamento entre oferta e demanda de energia. No Brasil, os preços de liquidação da diferença (PLD) estarão diretamente relacionados a esta falta de energia, haja vista serem o preço spot da energia neste mercado.

Hirth (2013), após avaliar o preço da energias renováveis variáveis (as energias solar e eólica dependem da taxa de incidência dos raios solares e da qualidade dos ventos, respectivamente), percebeu que a intermitente velocidade dos ventos e radiação solar afetam os preços da energia no mercado. Além disso, a tecnologia utilizada deve ser compatível com o meio em que se quer explorar os ventos. Katsigiannis e Stavrakakis (2013) chegaram à conclusão de que as melhores classes de turbinas conseguem produzir até 50\% mais energia que as de menor capacidade, independente do local e do regime de ventos.

Na simulação realizada por Kitapbayev, Moriarty e Mancarella (2014), em que leva em consideração as premissas de uma usina CHP, o DCF é obsoleto, sendo adotado um modelo de opções reais (RO - real options), já que não consegue captar as vicissitudes operacionais dos sistemas elétricos. Em plantas de energia hidráulica (hidrelétricas), ao invés do calor, podemos estocar a matéria prima em represas, de modo que, em períodos de estiagem cíclica, haja como garantir o 
abastecimento de energia.

Loisel et al. (2010), pesquisando o mercado de estocagem de energia na Europa em comparação com as redes de distribuição e suas possíveis falhas, utiliza o exemplo de uma planta eólica conectada ao mercado e ao depósito de energia, que serviria como backup para possíveis falhas na rede de distribuição, picos de demanda, e queda na qualidade dos ventos (variações que podem ser sazonais, mensais, semanais ou diárias), chegando à conclusão de que a estocagem de energia pode ser crucial na receita da empresa, haja vista a possibilidade de arbitragem no mercado spot de energia.

Frondel e Schmidt (2014) também chegaram a conclusões interessantes sobre o risco (as incertezas) atinentes ao suprimento energético dos países, destacando três: a contribuição própria do país no suprimento total de qualquer combustível; a quantidade de combustível importada e a probabilidade de interrupções no fornecimento por parte dos países exportadores, fatores que, de certa forma, influenciam nos já discutidos. Para seu modelo de risco energético, eles utilizam variáveis como a diversificação de fontes para a energia e na importação de combustíveis e energia, e as políticas de longo prazo e a estabilidade dos países exportadores.

No que tange à métrica $\mathrm{VaR}$ utilizada nessa dissertação, trata-se de uma forma de quantificação desenvolvida pelo banco JP Morgan (1996), resultando em uma forma sistemática resultante do esforço de determinar, a cada período, qual o valor de perda dado certo nível de significância estatística.

Dessa forma, um VaR 90\% traduz, em um número, que há 10\% de probabilidade de que um valor maior do que o indicado seja perdido. Por exemplo, para a distribuição de retornos de determinada carteira, o VaR 90\% corresponderá ao valor associado a um percentil extremo daquela distribuição, neste caso de 10\%. 


\section{3 \\ ENERGIA EÓLICA NO BRASIL E SUA COMERCIALIZAÇÃO}

Neste capítulo será apresentado como a inserção da energia eólica vem evoluindo no mundo e no Brasil (seções 3.1 e 3.2), bem como qual foi a evolução dos arranjos regulatórios e comerciais que viabilizam a comercialização de energia no Brasil, focando-se na comercialização no mercado livre, objeto desse estudo (seções 3.3 a 3.6).

\section{1}

\section{Um Breve Histórico Mundial}

Ao final de 2009, a capacidade instalada em plantas de geração eólica atingia a marca mundial de 158,5 GW (GWEC, 2010) no mundo, incluindo 2 GW em unidades off-shore. Na Figura 1 é mostrada a evolução da capacidade instalada mundial no período de 1996 a 2009 que, em termos médios, apresenta uma taxa de crescimento de $28 \%$ a.a..

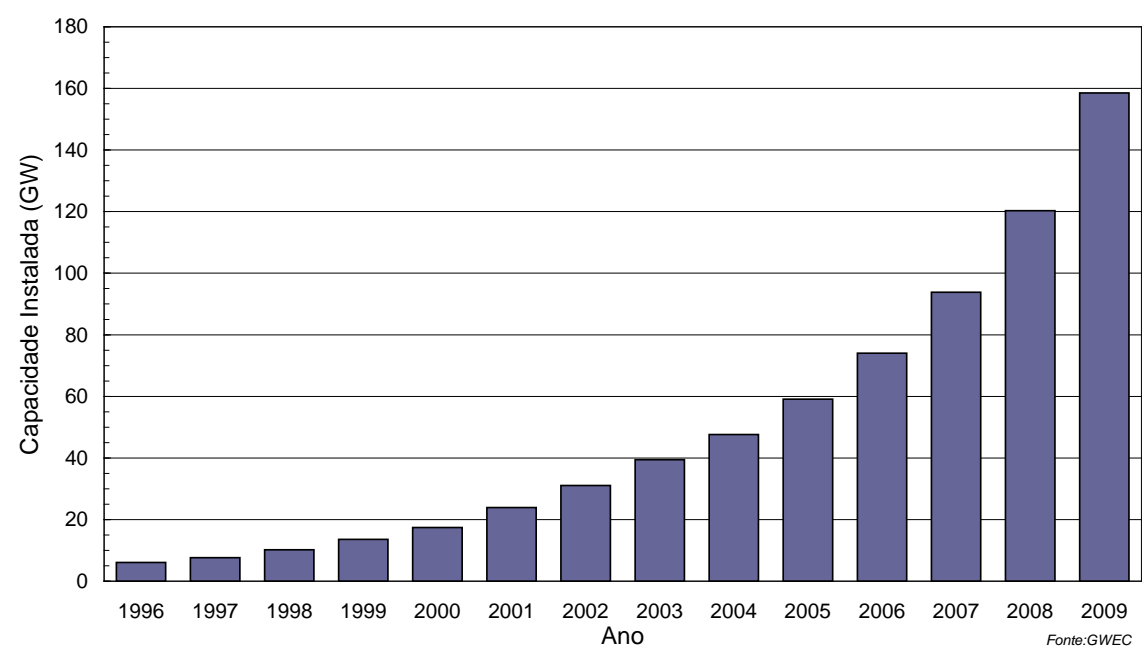

Figura 1: Evolução da Capacidade Instalada de Geração Eólica no Mundo.

Cerca de 50\% das plantas eólicas em operação no final do ano de 2009 encontravam-se na Europa, sobretudo na Alemanha $(25,8 \mathrm{GW})$ e na Espanha (19 GW), país onde se verificou o expressivo crescimento de 2,5 GW na capacidade instalada no período 2008-2009 (GWEC, 2010). Itália, França e Reino Uni- 
do têm entre 4 e 5 GW de capacidade instalada em plantas eólicas cada um, enquanto que Portugal e Dinamarca contribuem individualmente com cerca de 3,5 GW. Demais países europeus somavam em 2009 cerca de 11 GW. Era também na Europa que se encontravam a quase totalidade das plantas off-shore ao final de 2009, com destaque para o Reino Unido (0,87 GW), Dinamarca (0,65 GW) e Holanda (0,25 GW).

Na América Latina, com pouco mais de 1,2 GW de capacidade instalada ao final de 2009, o Brasil era o destaque regional com cerca de 0,6 GW em dois pólos de geração, nos estados do Ceará e do Rio Grande do Sul.

Até 2009, portanto, já era observada uma tendência de crescimento exponencial da energia eólica no mundo, e no Brasil não foi diferente.

\section{2}

\section{O Potencial de Crescimento da Energia Eólica no Brasil}

Não há dúvida de que o Brasil é uma potência energética, e a energia eólica se insere nesse contexto. A Figura 2 a seguir apresenta o potencial eólico brasileiro segundo Atlas levantado pelo Cepel/Eletrobrás. Observa-se que só o potencial do Nordeste (75 GW) já é maior que todo o consumo atual de energia no País (em torno de $65 \mathrm{GW})$.

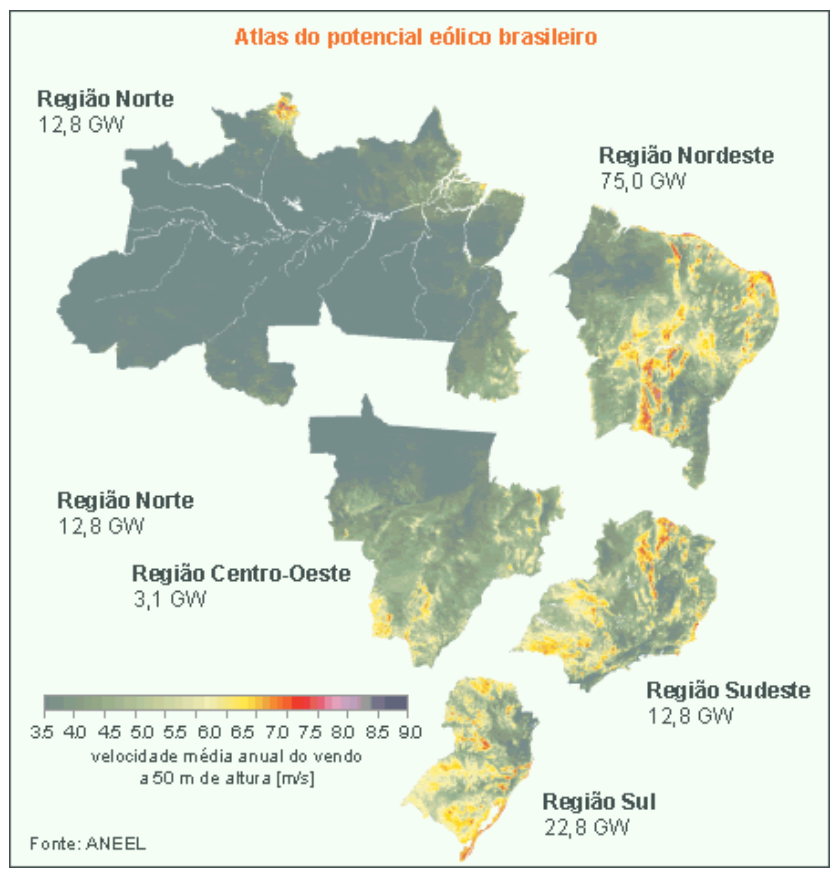

Figura 2: Atlas Eólico Brasileiro. 
De fato a energia eólica no Brasil tem muito espaço para crescer. O Plano Decenal de Expansão da Energia - PDE 2017, elaborado em 2008, fazia uma previsão que em 2017, 1\% da capacidade instalada no Brasil seria de fonte eólica. O PDE 2019, emitido em 2010, estimava uma capacidade instalada de 4\% em 2019. O PDE 2020, emitido em 2011, projetava para 2020, um percentual de quase $7 \%$ da matriz elétrica nacional formada por parques eólicos.

Os crescentes sinais de investimentos no setor eólico podem ser observados através dos resultados dos leilões de energia 2009, 2010 e 2011, que contrataram mais de 5.700 MW dessa fonte e foram implementados até 2014, levando a geração eólica de 1.093 MW (ANEEL, 2011) instalados em março de 2011 para 7.200 MW em 2014, um incremento de 85\% em pouco mais de 3 anos.

\section{3}

\section{A Evolução Regulatória e Comercial no Brasil}

O primeiro programa de incentivo a energia eólica no Brasil surgiu em 2001, Programa Emergencial de Energia Eólica, PROEÓLICA, foi criado através da Resolução n 24, de 5 de julho de 2001 (Planalto, 2011), da Câmara de Gestão da Crise de Energia Elétrica, a CGE, com objetivo de implantar 1.050 MW de eólica interligada ao SIN até dezembro de 2003. Para atingir essa meta, a Resolução estabelecia garantia de aquisição da energia gerada por 15 anos pela Eletrobrás, que seria repassada para as tarifas. No entanto, o programa falhou em seu objetivo, principalmente pelo curto prazo que os investidores tinham para conseguir os benefícios e também pela falta de regulamentação apropriada, que estabelecesse de forma clara e objetiva as metas e os benefícios do programa.

Em 2002, o governo federal, através da Lei 10.438, de abril de 2002, criou o Programa de Incentivo a Fontes Alternativas de Energia - PROINFA, que seria executado em duas fases. A primeira delas definia que 3.300 MW de energia proveniente de eólicas, térmicas a biomassa e PCHs deveriam ser conectadas ao sistema interligado nacional até 2006. Para a segunda fase, a meta era atingir 10\% da matriz elétrica em fontes renováveis alternativas em 2022. A primeira fase, apesar de ter como data 2006, já sofreu algumas postergações e o prazo final para implantação atual é dezembro de 2011. 
O PROINFA trouxe alguns incentivos para os investidores tais como, toda a energia foi vendida para a Eletrobrás, por 20 anos, a tarifas fixas, reajustáveis anualmente pela inflação (IGP-M) e definidas de modo a garantir a viabilidade econômico-financeira de projetos-padrão, no local de implantação, os geradores não têm que fornecer estimativas/compromissos de geração; o BNDES financiava $70 \%$ do investimento em eólicas, por até 10 anos, posteriormente o financiamento pode ser até $80 \%$ por 14 anos; o BNB também financiou eólicas por até 20 anos, a taxas fixas e subsidiadas e com 2 anos de carência; 50\% de redução nas tarifas de transmissão e distribuição para parques eólicos menores que 30 MW (Res. ANEEL 219, 23.04.2003).

A segunda fase do PROINFA não chegou a acontecer devido às mudanças na forma de contratação de energia no país a partir de 2004, com ênfase na modicidade tarifária e em leilões de menor preço.

\section{4 \\ Modelo Atual de Comercialização de Energia}

Conforme explicado no Capítulo 2, em 2004, o governo federal, através das Leis $n^{\circ} 10.847$ e 10.848 , de 15 de março de 2004; e pelo Decreto ${ }^{\circ}$ 5.163, de 30 de julho de 2004 estabeleceu as bases de um novo modelo para o Setor Elétrico Brasileiro.

Em relação à comercialização de energia, foram instituídos dois ambientes para celebração de contratos de compra e venda de energia: o Ambiente de Contratação Regulada (ACR), no qual participam Agentes de Geração e de Distribuição de energia; e o Ambiente de Contratação Livre (ACL), onde participam Agentes de Geração, Comercializadores, Importadores e Exportadores de energia e Consumidores Livres.

O modelo prevê a exigência de contratação de totalidade da demanda por parte das distribuidoras no ambiente regulado por meio de leilões - observado o critério de menor preço, objetivando a redução do custo de aquisição da energia elétrica a ser repassada para a tarifa dos consumidores cativos (Tolmasquim, 2011). Desta forma, a comercialização de energia eólica para as distribuidoras só pode ser realizada através de leilões de energia. Por outro lado, os empreendedo- 
res podem também comercializar sua energia no ambiente livre, através dos contratos bilaterais, sendo este o foco desta dissertação.

Apenas para contextualizar, apresenta-se na próxima seção o formato de contratação no ambiente regulado.

\section{5}

\section{Contratação de Energia no ACR: Leilões de Energia}

O MME promove, anualmente, juntamente com a ANEEL, a realização de leilões para atender à demanda das distribuidoras. Para isso, o MME estabelece, em portaria, a data dos leilões, que são realizados pela CCEE, por delegação da ANEEL que fixa o preço-teto (R\$/MWh), e é indicado nos editais dos respectivos leilões. Os agentes vendedores que oferecem os menores preços em relação ao preço-teto são os vencedores do leilão e então celebram os Contratos de Comercialização de Energia Elétrica no Ambiente Regulado (CCEAR) que regulam os direitos e os deveres de compra/venda de energia entre os agentes geradores vitoriosos e os distribuidores que participaram do leilão.

Para participar dos leilões, os empreendedores devem fazer o cadastramento do empreendimento junto a EPE para fins de habilitação técnica e participar do leilão. A EPE analisa os estudos, dados e parâmetros fornecidos pelos investidores e habilita, ou não, tais projetos. Nessa fase de habilitação, quando a conexão do parque eólico é pretendida na rede básica, o ONS é consultado com relação à viabilidade técnica da conexão de cada parque individualmente, pois não se sabe quem serão os vencedores e emite o documento de acesso, que é um pré-requisito para habilitação técnica junto a EPE. Quando a pretensão da conexão do parque é na rede de distribuição, a consulta é feita à distribuidora detentora da concessão da área geográfica, que emite documento similar.

Os leilões são classificados de acordo com uma sequência temporal de eventos de compra de energia para os distribuidores no ACR. Essa sequência permite que os distribuidores gerenciem as incertezas associadas à evolução da demanda. Os leilões podem ser realizados para entrega da energia no ano atual do leilão ou até 5 anos após a realização do leilão, sendo “A” como o ano previsto para o início do suprimento de energia elétrica adquirida pelos agentes de distribuição nos leilões de energia.Os leilões de energia nova são A-3 ou A-5, ou seja, com data de 
entrega da energia 3 ou 5 anos após o ano de realização do leilão, respectivamente.

\section{6}

\section{Contratação no ACL e a Diferença de PLDs Entre Submercados}

Conforme já mencionado, o parque eólico pode contratar sua energia no ACL. Para fins de financiamento de longo prazo na estrutura de Project Finance é comum que esse contrato de venda seja de longo prazo, normalmente de 15 a 20 anos.

É comum também que o contrato seja realizado no submercado sudeste onde há bem mais liquidez e uma demanda muito maior por energia. Dessa forma, como o parque eólico em geral se encontra no Nordeste (e esse é o caso abordado nessa dissertação), o investidor/empreendimento passa a correr um risco de submercado na contabilização financeira executada pela CCEE.

O problema da diferença de PLDs entre submercados aparece uma vez que a energia gerada no NE é liquidada ao PLD NE e a energia entregue no submercado SE devido ao registro da venda bilateral é “recomprada” ao PLD SE para ser entregue segundo o sistema de compensação. Dessa forma, caso haja uma diferença nos PLDs o empreendimento corre risco de perda financeira na liquidação.

Os PLDs podem ser diferentes entre os submercados pois as condições de oferta, demanda, e, principalmente, estoque de água podem ser muito distintas. Além disso, os intercâmbios entre os submercados têm limites, não sendo o suprimento entre submercados sempre pleno.

Como exemplo, seja um contrato de 15 MWmed, feito entre um parque eólico do nordeste e uma comercializadora do sudeste. Seja também um momento dos submercados em que o PLD no NE está em 100 R\$/MWh e o do SE em 200 R\$/MWh. Em um mês com 720 horas, o contrato corresponde a 15 x $720=$ 10.800 MWh, e irá apresentar uma liquidação negativa ou devedora na CCEE de $10.800 \times(100-200)=1.080 .000 \mathrm{R} \$$.

Essa situação será objeto de simulação e análise, sendo os resultados apresentados no próximo capítulo. 


\section{RESULTADOS E ANÁLISE}

Foi realizada uma simulação de Monte Carlo a partir do modelo Newave pela qual se pode analisar o risco de submercado de um parque eólico que se encontra no nordeste e vende sua energia no sudeste. A Figura $\mathrm{x}$ a seguir mostra os PLDs médios para o ano de 2015, evidenciando o risco que o parque eólico corre no ano de 2015 uma vez que os PLDs médios do nordeste são menores.

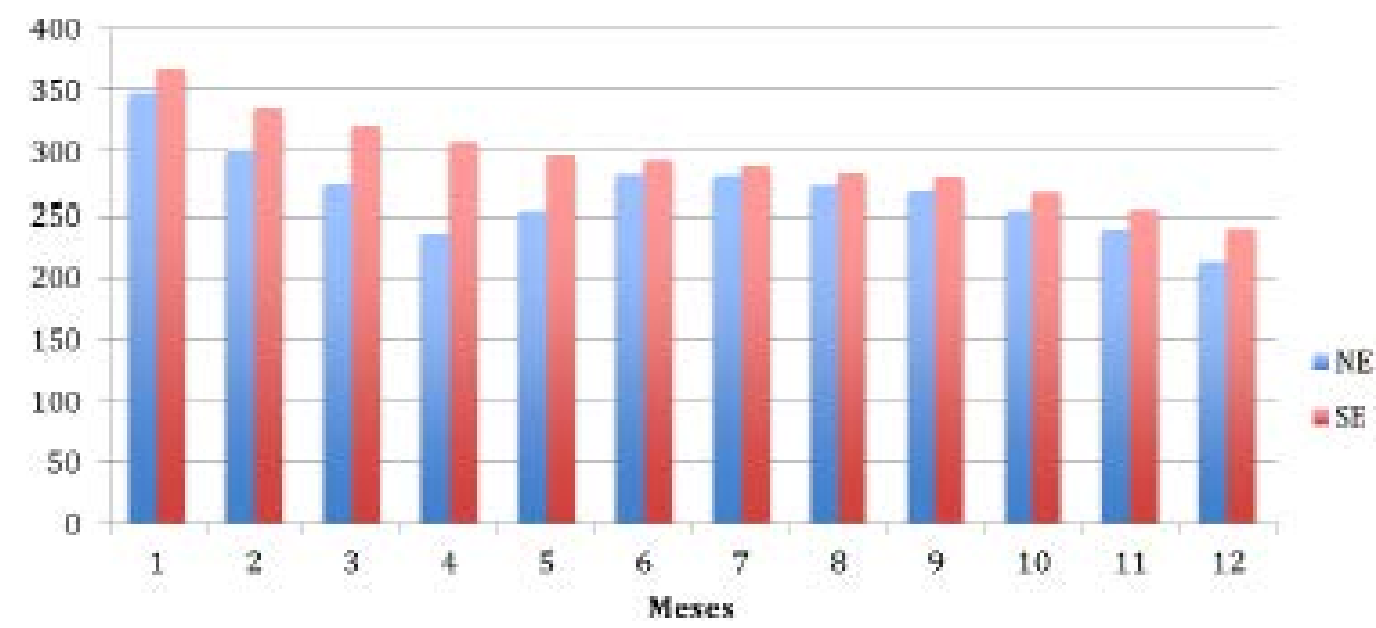

Figura 3: Comparativo gráfico entre os PLDs Médios SE x NE (2015).

Como há uma oferta de energia complementar no nordeste quer seja de fonte térmica ou eólica, a expectativa de preços futuros fica menor neste submercado.

A tabela 2 adiante apresenta os valores dos PLDs médios e as respectivas diferenças percentuais. Observa-se que a diferença chega a ser de 23\% no mês de Abril, o que pode representar perdas da ordem de R\$ 2 milhões em um único mês para um parque eólico de 30 MWmed de capacidade instalada.

É possível notar ainda que as diferenças de PLDs são maiores no período úmido, e ficam bem menores no período seco. Este resultado deve estar aparecendo devido a uma combinação de sobre oferta e replecionamento dos reservatórios do nordeste no fim do período úmido, culminando em PLDs mais baixos comparativamente aos do sudeste. 
Tabela 2: PLD médio esperado de 2015.

\begin{tabular}{|c|c|c|c|}
\hline & $\mathrm{NE}$ & SE & $\Delta$ \\
\hline Janeiro & 347,05 & 368,22 & $6 \%$ \\
\hline Fevereiro & 301,36 & 335,38 & $10 \%$ \\
\hline Março & 275,01 & 320,74 & $14 \%$ \\
\hline Abril & 235,79 & 308,18 & $23 \%$ \\
\hline Maio & 253,94 & 296,83 & $14 \%$ \\
\hline Junho & 281,99 & 293,49 & $4 \%$ \\
\hline Julho & 279,98 & 288,63 & $3 \%$ \\
\hline Agosto & 273,79 & 282,98 & $3 \%$ \\
\hline Setembro & 268,78 & 278,73 & $4 \%$ \\
\hline Outubro & 254,25 & 267,92 & $5 \%$ \\
\hline Novembro & 238,87 & 255,76 & $7 \%$ \\
\hline Dezembro & 213,62 & 239,83 & $11 \%$ \\
\hline
\end{tabular}

Considerando agora a distribuição de frequências das diferenças de PLDs (SE - NE) para uma amostra de 2000 séries simuladas, observa-se pela figura $x$ que há uma relevante assimetria, sendo que a maior parte dos valores encontramse entre 10 e $20 \mathrm{R} \$ / \mathrm{MWh}$, contudo, com menor probabilidade são verificadas diferenças da ordem de $60 \mathrm{R} \$ / \mathrm{MWh}$. A Figura 4 que se segue apresenta a distribuição.

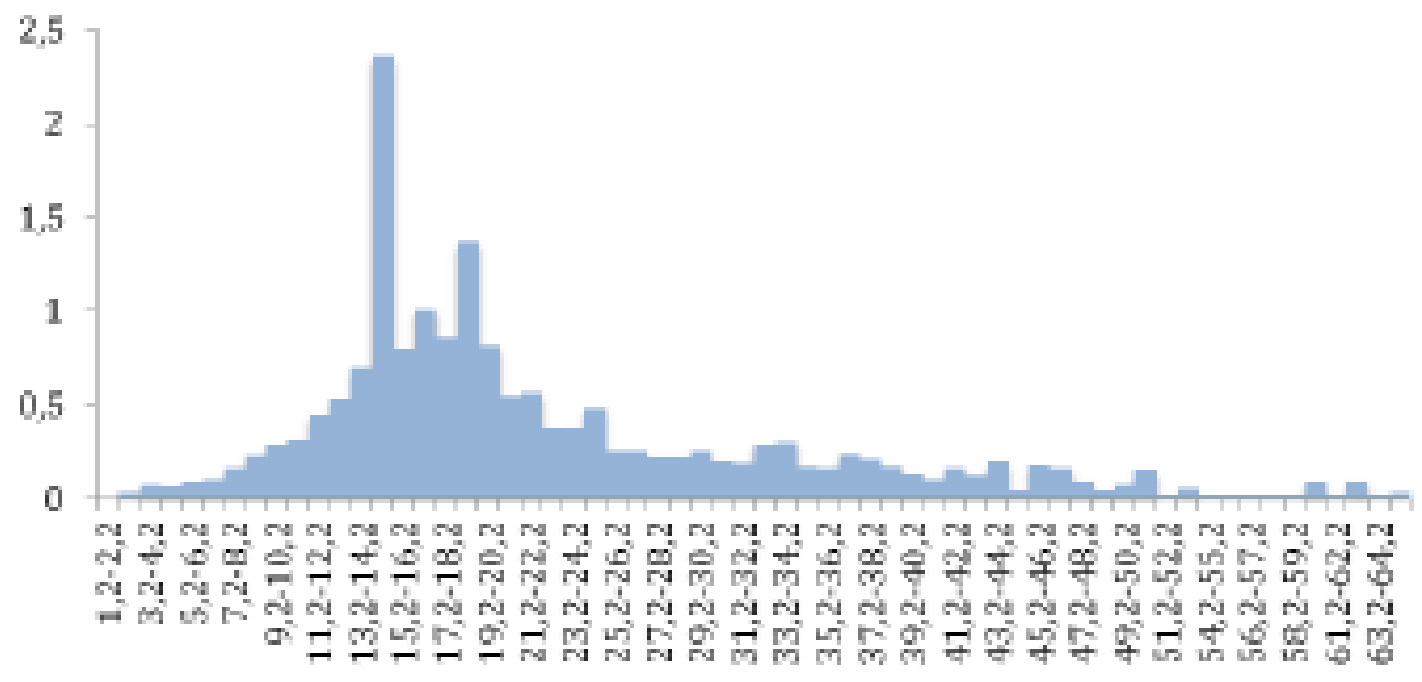

Figura 4: Distribuição de frequências da média das diferenças dos PLD. 
Tendo sido observadas as características das diferenças de PLDs, pode-se agora confrontar a sazonalidade de geração de energia com a sazonalidade das diferenças.

Conforme analisado na tabela 3, as diferenças de PLDs são maiores de fevereiro a maio, justamente o período de menor geração de um parque eólico típico do litoral do Ceará ou do Rio Grande do Norte (Figura 5).

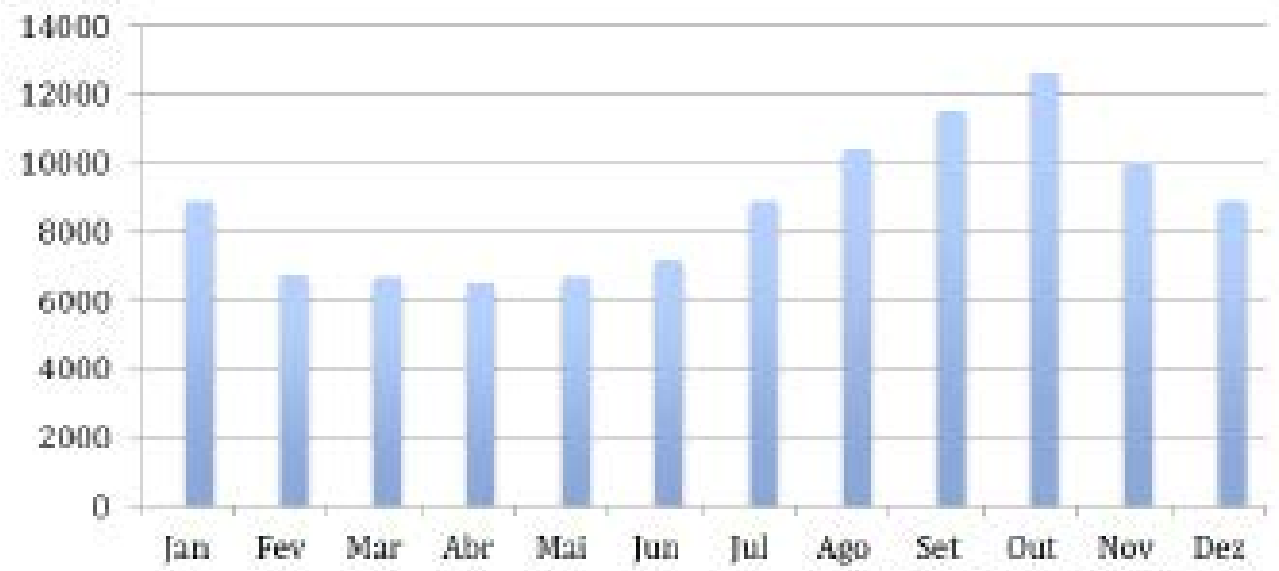

Figura 5: Produção de energia de usina eólica.

Esse é um aspecto positivo quando se olha para as duas curvas em conjunto, pois em quantidade a exposição é menor justamente no período em que as diferenças desfavoráveis de preço são maiores.

Passando a analisar o triênio 2016-2018, foi feita agora uma simulação de resultado em ( $\mathrm{R}$ x 1000) para um parque eólico típico do nordeste que vende sua energia no sudeste. A Figura 6 adiante apresenta os resultados da simulação. 


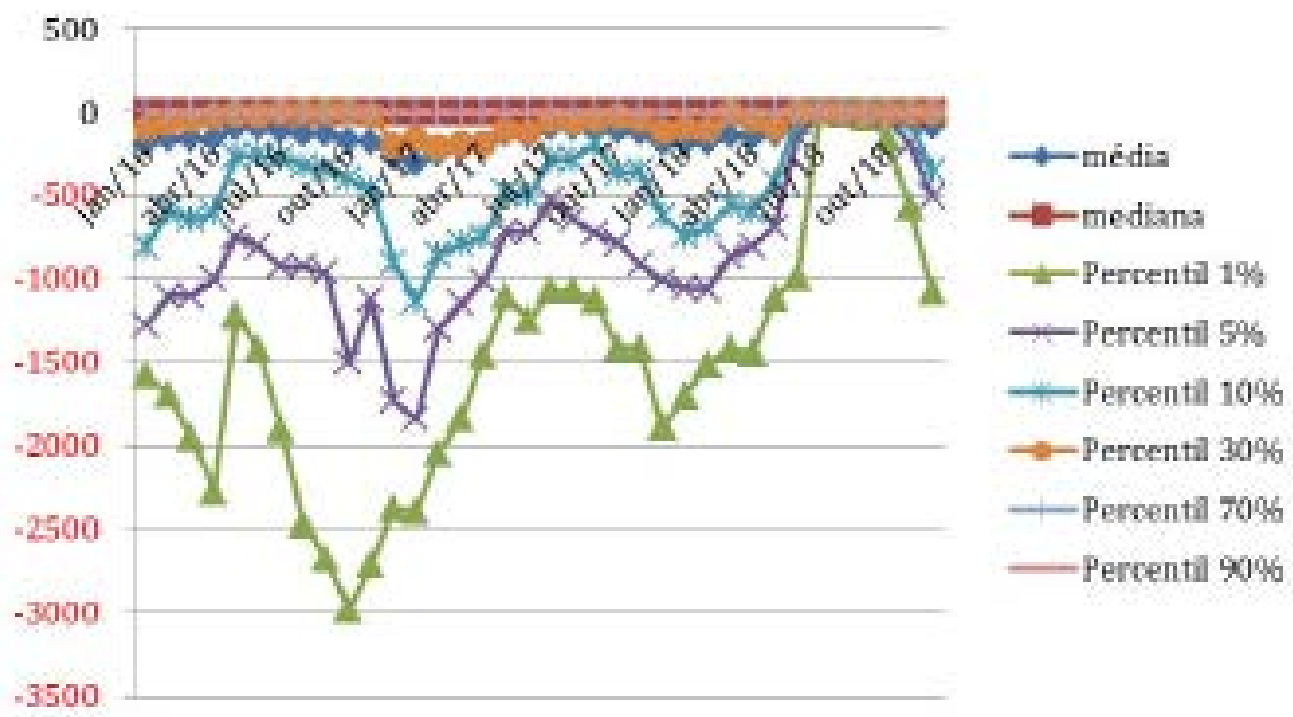

Figura 6: Valores Mensais em Risco.

A diferença entre os PLDs SE e NE permanece positiva, o que significa que os preços da energia no sudeste são também maiores em média entre 2016 e 2018, refletindo em um resultado médio negativo para o parque eólico no que tange ao risco de submercado, conforme observado na figura anterior.

Observa-se, ainda, pela figura, que o nível de risco extremo (percentil 1\%, ou $\mathrm{VaR}_{99 \% \text {,mês }}$ ) chega a ser de 3 milhões de R\$ em um único mês, estando ao longo de quase todo o período na casa dos 2 milhões de R\$ por mês.

Conclui-se, portanto, que esse não é um risco tolerável pelo investidor e, conforme comentado no capítulo 1, o risco só aparece por uma falta de liquidez nos contratos no nordeste.

O investidor, por sua vez, pode realizar um hedge descruzando a exposição ao submercado, fazendo uma operação de swap de submercado ou de compra de energia no sudeste e venda no nordeste. Na situação do swap de submercado, entrega-se energia no nordeste em troca de energia no sudeste.

A fim de evidenciar a mitigação de risco, principal objetivo deste trabalho, considera-se que foi realizado um swap de submercado de 12 MWmed com outro agente que tivesse interesse na posição contrária.

A figura 7 a seguir mostra a exposição à diferença de submercado com o swap realizado. O nível de risco extremo diminui bastante, e pode-se observar que a média fica praticamente nula. $\mathrm{O} \mathrm{VaR}_{95 \%}$, por exemplo, não passa de $400 \mathrm{mil}$ reais. 


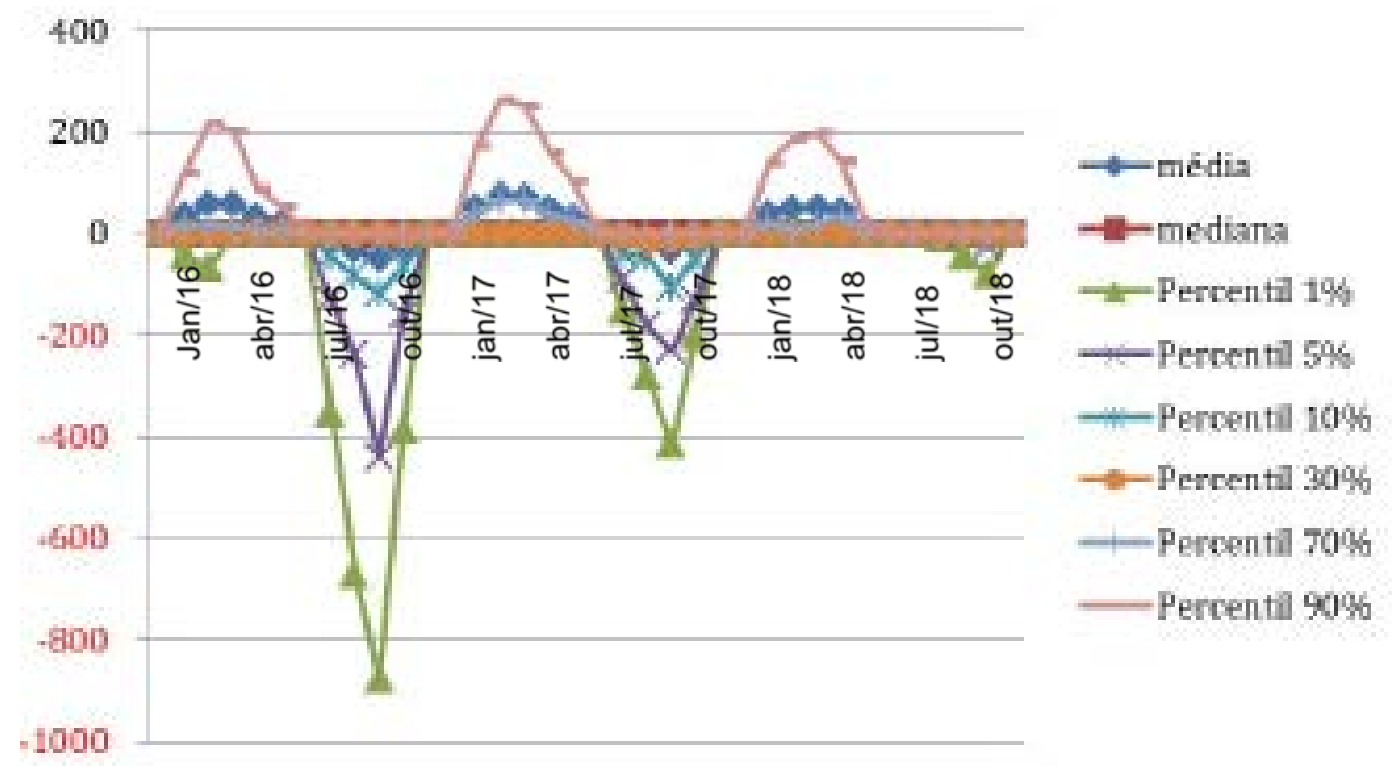

Figura 7: Simulação - swap 12 MWmed.

Assim, fica mostrado que os swaps de submercado são instrumentos contratuais eficazes para a mitigação de risco de um parque eólico no NE com venda no SE.

O investidor do parque eólico estaria até disposto a pagar um prêmio pelo swap, uma vez que a mitigação de risco é evidente. Contudo, é comum o mercado trabalhar com prêmio nulo, dado que a outra ponta do swap também percebe um risco grande quando não o realiza.

Dessa forma, em havendo liquidez para o instrumento de swap, os empreendedores eólicos podem sem maiores riscos continuarem vendendo sua energia no sudeste, submercado este com demanda muito maior no ACL. 


\section{5 CONCLUSÕES E SUGESTÕES PARA TRABALHOS FUTU- ROS}

O propósito desse trabalho foi o de apresentar o risco de submercado assumido por empreendimentos eólicos entre nordeste e sudeste com comercialização no ACL. O risco foi evidenciado por métricas como o Value at Risk a partir da simulação de preços spot para ambos os mercados.

Além disso, foi mostrado como esse risco pode ser mitigado com instrumentos contratuais disponíveis no mercado, bem como qual é o nível de eficácia desses instrumentos.

Assim, a seguinte questão de pesquisa pôde ser trabalhada: “Qual é a magnitude do risco de submercado enfrentado por empreendimentos eólicos que vendem energia no ACL no sudeste e qual é a eficácia de instrumentos de hedge disponíveis no mercado? ”

Foi realizada uma simulação de Monte Carlo a partir do modelo Newave (dados de agosto/2014) pela qual se pôde analisar o risco de submercado de um parque eólico que se encontra no nordeste e vende sua energia no sudeste.

Foi possível notar que as diferenças de PLDs são maiores no período úmido, e ficam bem menores no período seco. Este resultado deve estar aparecendo devido a uma combinação de sobre oferta e replecionamento dos reservatórios do nordeste no fim do período úmido, culminando em PLDs mais baixos comparativamente aos do sudeste.

Analisando o triênio 2016-2018, foi feita uma simulação de resultado em (R \$1000) para um parque eólico típico do nordeste que vende sua energia no sudeste. Constatou-se que a diferença entre os PLDs SE e NE permanece positiva, o que significa que os preços da energia no sudeste são também maiores em média entre 2016 e 2018, refletindo em um resultado médio negativo para o parque eólico no que tange ao risco de submercado, conforme observado na figura anterior.

Observou-se, ainda, que o nível de risco extremo (percentil 1\%, ou VaR ${ }_{99 \% \text {,mês }}$ ) chegou a ser de 3 milhões de $\mathrm{R}$ \$ em um único mês, estando ao longo de quase todo o período na casa dos 2 milhões de R\$ por mês. 
Foi concluído que esse não é um risco tolerável pelo investidor e, conforme comentado no capítulo 1, o risco só aparece por uma falta de liquidez nos contratos no nordeste.

O investidor, por sua vez, pode realizar um hedge descruzando a exposição ao submercado, fazendo uma operação de swap de submercado ou de compra de energia no sudeste e venda no nordeste. Na situação do swap de submercado, entrega-se energia no nordeste em troca de energia no sudeste.

A fim de evidenciar a mitigação de risco, principal objetivo deste trabalho, considerou-se que foi realizado um swap de submercado de 12 MWmed com outro agente que tivesse interesse na posição contrária.

Assim, ficou evidenciado que os swaps de submercado são instrumentos contratuais eficazes para a mitigação de risco de um parque eólico no NE com venda no SE.

Dessa forma, em havendo liquidez para o instrumento de swap, os empreendedores eólicos podem sem maiores riscos continuarem vendendo sua energia no sudeste, submercado este com demanda muito maior no ACL.

Com esse trabalho foi possível mostrar a eficácia dos instrumentos de proteção para o risco de submercado assumido por parques eólicos. Em sendo eficazes, esses instrumentos propiciam mais segurança para que se tenham mais investimentos em geração eólica com venda no sudeste.

Os investimentos em energia eólica no nordeste do Brasil com venda em todo o país são importantes por se tratarem de investimentos em fontes renováveis de energia e por promoverem mais energia de forma competitiva para a indústria brasileira, principal consumidor do ACL.

Como sugestões para trabalhos futuros, primeiramente, pode-se pensar na elaboração de um modelo de precificação dos prêmios de risco entre submercados. Também é um aprimoramento considerar a simulação de geração do parque eólico e não somente a simulação de PLDs. 


\section{REFERÊNCIAS BIBLIOGRÁFICAS}

EPE - Empresa de Pesquisa Energética, projeção a demanda de energia elétrica para os próximos dez anos (2013-2022)., Rio de Janeiro, 2012

FRONDEL, M., SCHMIDT, C. M. A measure of nation's physical energy supply risk. The Quaterly Review of Economics and Finance. vol 54, p. 208-215, 2014

HIRTH, L. The market value of variable renewables. The effect of solar wind power variability on their relative price. Energy Economics. vol. 38, p. 218-236, 2013

JUNG, J., BROADWATER, R. P. Current status and future advances for wind speed and power forecasting. Renewable and Sustainable Energy Reviews. vol. 31, p. 762-777, 2014

J.P. Morgan (1996). Risk Metrics. Technical Document, New York.

KATSIGIANNIS, Y. A., STAVRAKAKIS, G. S. Estimation of wind energy production in various sites in Australia for different wind turbine classes: A comparative technical and economic assessment. Renewable Energy. vol. 67, p. 230-236, 2014

KITAPBAYEV, Y., MORIARTY, J., MANCARELLA, P. Stochastic control and real options valuation of thermal storage-enabled demand response from flexible district energy systems. Applied Energy. article in press, 2014

LOISEL, R. et al. Valuation framework for large scale electrictity storage in a case with wind curtailment. Energy Policy. vol. 38, p. 7323-7337, 2010

Maceira, M. E. P.; Bezerra C. V. (1997). Stochastic stream flow model for hydroelectric systems. Proceedings of PMAPS.

Maceira M.E.P; Mercio C.B.; Gorenstin B.G.; Cunha S.H.F; Suanno C.; Sacramento M.C.; Kligerman A. (1998): Application of the NEWAVE Model in the Energy Evaluation of the Brazilian North/Northeast and South/Southeast Interconnected Systems, VI Symposium of Specialists in Eletric Operational and Expansion Planning, Salvador, Brazil.

MENEGAKI, A. Valuation for renewable energy: A comparative review. Renewable and Sustainable Energy Reviews. vol. 12, p. 2422-2437, 2008.

MIRASGEDIS, S. et al. Valuing the visual impact of wind farms: An application in South Evia, Greece. Renewable and Sustainable Energy Reviews. vol. 39, p. 296-311, 2014. 
Pereira M. V. F.; Pinto L. M. V. G. (1991). Multi-stage stochastic optimization applied to energy planning. Mathematical Programming, 52.

XU, M., ZHUAN, X. Optimal planning for wind power capacity in an electric power system. Renewable Energy. vol. 53, p. 280-286, 2013 